\title{
Protein tyrosine nitration in higher plants grown under natural and stress conditions
}

\author{
Francisco J. Corpas ${ }^{1}{ }^{*}$, José M. Palma ${ }^{1}$, Luis A. del Río ${ }^{1}$ and Juan B. Barroso ${ }^{2}$ \\ Departamento de Bioquímica, Biología Celular y Molecular de Plantas, Estación Experimental del Zaidín, Consejo Superior de Investigaciones Científicas, \\ Granada, Spain \\ ${ }^{2}$ Grupo de Señalización Molecular y Sistemas Antioxidantes en Plantas, Unidad Asociada al Consejo Superior de Investigaciones Científicas (EEZ), Área de \\ Bioquímica y Biología Molecular, Universidad de Jaén, Jaén, Spain
}

Edited by:

lan M. Møller, Aarhus University,

Denmark

Reviewed by:

Ian M. Møller, Aarhus University, Denmark

Kim H. Hebelstrup, University of Aarhus, Denmark

Abir U. Igamberdiev, Memorial University of Newfoundland, Canada

*Correspondence:

Francisco J. Corpas, Departamento de Bioquímica, Biología Celular y

Molecular de Plantas, Estación

Experimental del Zaidín, Consejo

Superior de Investigaciones

Científicas, Apdo. 419, E-18080

Granada, Spain.

e-mail: javier.corpas@eez.csic.es
Protein tyrosine nitration is a post-translational modification (PTM) mediated by reactive nitrogen species (RNS) that is linked to nitro-oxidative damages in plant cells. During the last decade, the identification of proteins undergoing this PTM under adverse environmental conditions has increased. However, there is also a basal endogenous nitration which seems to have a regulatory function. The technological advances in proteome analysis have allowed identifying these modified proteins and have shown that the number and identity of the nitrated proteins change among plant species, analysed organs and growing/culture conditions. In this work, the current knowledge of protein tyrosine nitration in higher plants under different situations is reviewed.

Keywords: nitric oxide, nitroproteome, peroxynitrite, reactive nitrogen species (RNS), tyrosine nitration

\section{INTRODUCTION}

Protein tyrosine nitration is a post-translational modification (PTM) mediated by nitric oxide-derived molecules. It is the result of the addition of a nitro $\left(-\mathrm{NO}_{2}\right)$ group to one of two equivalent ortho carbons in the aromatic ring of tyrosine residues (Gow et al., 2004). This process can alter protein function because the incorporation of this nitro group into the aromatic ring lowers the pKa of the phenolic group from 10.1 of the tyrosine to 7.2 in the nitrotyrosine (Sokolovsky et al., 1967; Abello et al., 2009). This provokes both steric and electronic perturbations that affect Tyr's capacity to function in electron-transfer reactions and to maintain protein conformation (van der Vliet et al., 1999). Tyrosine nitration can change the function of the protein in several ways: function gain; no effect on function; and inhibition of function, the latter being the most common consequence of tyrosine nitration (Greenacre and Ischiropoulos, 2001; Radi, 2004). On the other hand, tyrosine nitration may influence many signal transduction pathways because this modification prevents phosphorylation of tyrosine and consequently affects one regulatory mechanism (Galetskiy et al., 2011).

The presence of nitrotyrosine has been considered as a footprint of the occurrence of the strong nitrating agent peroxynitrite $\left(\mathrm{ONOO}^{-}\right)$, a reactive nitrogen species (RNS), which is formed usually under stress conditions by the chemical reaction between two radicals, nitric oxide $\left({ }^{\circ} \mathrm{NO}\right)$ and superoxide anion $\left(\mathrm{O}_{2}^{--}\right)$ (Ischiropoulos, 2003; Chaki et al., 2009a; Arasimowicz-Jelonek and Floryszak-Wieczorek, 2011). However, there is another potential mechanism involving a hemoperoxidase that, in the presence of hydrogen peroxide $\left(\mathrm{H}_{2} \mathrm{O}_{2}\right)$ and nitrite $\left(\mathrm{NO}_{2}^{-}\right)$, can generate the radical nitrogen dioxide $\left({ }^{-} \mathrm{NO}_{2}\right)$ which acts as a nitrating agent (Souza et al., 2008) (Figure 1A). A relevant aspect is that tyrosine nitration is not a random process because not all Tyr residues are susceptible to nitration which depends on their accessibility to the solvent. Tyrosine has a hydropathy index of -1.3 being a mildly hydrophilic amino acid and, therefore, most likely exposed to the aqueous environment.

In most proteins, the number of tyrosine residues is around $3-4 \%$ out of the primary structure, but only few of these tyrosines may become preferentially nitrated. A good example is the human serum albumin which has $18 \mathrm{Tyr}$ residues, and under in vitro nitration by peroxynitrite only 2 Tyr are susceptible of nitration. In animal organisms, the number of nitrotyrosine-containing proteins identified by proteomics approaches ranges from few proteins to over 100, depending on the organ (brain, heart, liver, etc.), subcellular compartment, and physiological conditions (normal or stress situations) (Abello et al., 2009).

\section{In vivo DETECTION OF PROTEIN TARGETS OF TYROSINE NITRATION IN PLANTS}

In higher plants, tyrosine nitration was initially detected using 1D gel electrophoresis followed by immunoblotting probed with antibodies against 3-nitrotyrosine. Thus, in tobacco leaf extracts and BY2 cell cultures it was observed that the exogenous application of nitrating agents such as peroxynitrite provoked a rise of immunoreactive proteins (Morot-Gaudry-Talarmain et al., 2002; Saito et al., 2006). Later, a similar behavior in the profile of nitrated proteins was observed in leaves of olive plants grown with $200 \mathrm{mM} \mathrm{NaCl}$ which induced both oxidative and 


\section{A

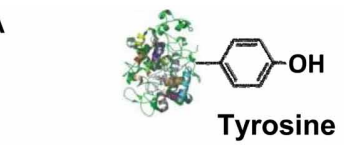

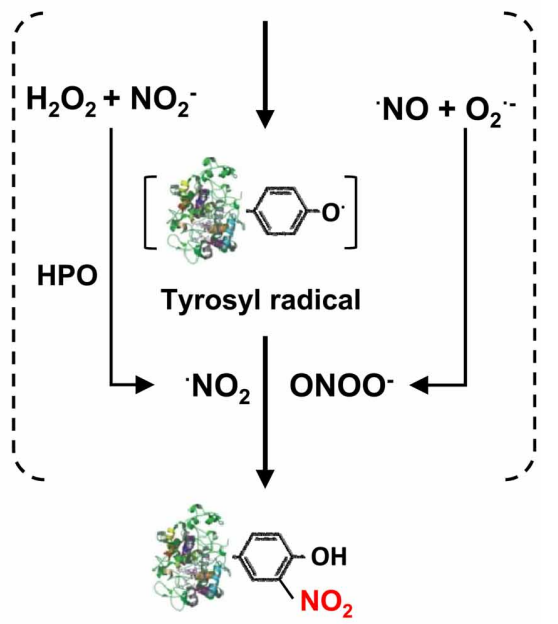

3-nitrotyrosine

B

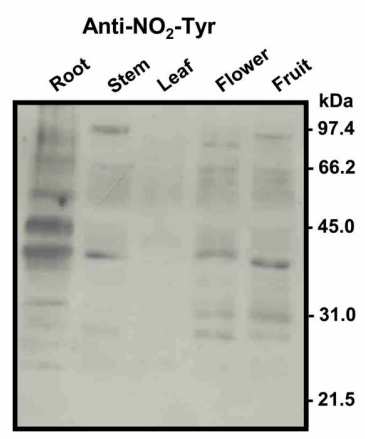

FIGURE 1 | (A) Biochemistry of protein tyrosine nitration $\left(\mathrm{NO}_{2}\right.$-Tyr). Tyrosine nitration involves two steps: oxidation of the phenolic ring of tyrosine to tyrosyl radical (Tyr') and addition of ' $\mathrm{NO}_{2}$ to the Tyr' by a nitrating agent. The Tyr radical can be produced by several one-electron oxidants such as $\mathrm{NO}_{2}, \mathrm{OH}^{\mathrm{O}}$, or $\mathrm{CO}_{3}^{-}$. There are two main nitrating reactions: (1) by peroxynitrite $\left(\mathrm{ONOO}^{-}\right)$which is formed by the quick reaction between nitric oxide (' $\mathrm{NO}$ ) and superoxide $\left(\mathrm{O}_{2}^{-}\right)$radicals; and (2) $\mathrm{By} \cdot \mathrm{NO}_{2}$ produced by reaction of hydrogen peroxide $\left(\mathrm{H}_{2} \mathrm{O}_{2}\right)$ and nitrite $\left(\mathrm{NO}_{2}^{-}\right)$in the presence of hemoperoxidase (HPO) (Souza et al., 2008). (B) Representative immunoblot showing the pattern of protein tyrosine nitration $\left(\mathrm{NO}_{2}\right.$-Tyr) in different organs (root, stem, leaf, flower, and fruit) of pea plants after 71 days of growth under optimal conditions. The numbers on the right side of the immunoblots indicate the relative molecular masses of the protein markers (reproduced from Corpas et al., 2009).

nitrosative stresses (Valderrama et al., 2007). After detecting the proteins which underwent tyrosine nitration, the next step was to identity those proteins which were targets of this PTM. Thus, the combination of proteomic techniques (two-dimensional polyacryamide gel electrophoresis) followed by immunoblotting or immunoprecipitation, gel tryptic digestion and mass spectrometry have become powerful tools to develop nitroproteome studies in higher plants. Although there might be some technical problems like those due to the unspecific recognition of the antibody used against nitrotyrosine, the low number of nitrotyrosines in a given protein, the low abundance of the nitrotyrosinecontaining proteins, and that the isolated protein occasionally does not match in the protein database, it must be pointed out that these approaches have allowed establishing a basic background of knowledge in this research area (Dekker et al., 2012). In any case, after a specific protein has been identified as a putative nitration target, a necessary additional step is to identify the nitration site(s) within the protein quaternary structure by MALDI-TOF MS and LC-MS/MS (Ytterberg and Jensen, 2010). Finally, in vitro analyses of the physiological effects of nitration on the specific proteins must be developed. Table 1 summarizes some of the identified nitrated proteins in higher plants where the locus for the nitrated tyrosine residue have been identified and the physiological effect of this PTM established.

\section{NITRATION AND ENVIRONMENTAL STRESS SITUATIONS}

Tyrosine nitration has been mainly studied in plants under stress conditions and it is assumed that a rise in the protein tyrosine nitration is a reliable marker of nitro-oxidative stress (Corpas et al., 2007). A significant number of data in different organs and plant species support this idea since increases of some specific nitrated proteins under different abiotic and biotic stresses have been reported. Thus, this PTM event occurs in leaves from pea plants subjected to different abiotic stresses including low and high temperature (HT), continuous light, and high light intensity (Corpas et al., 2008), in olives leaves, in Arabidopsis roots and Citrus leaves under salinity stress (Valderrama et al., 2007; Corpas et al., 2009; Tanou et al., 2012), in sunflower hypocotyls infected by the pathogen Plasmopara halstedii (Chaki et al., 2009a), in Prunus genotypes under high bicarbonate and high $\mathrm{pH}$ (Cellini et al., 2011), in pepper leaves under low temperature (Airaki et al., 2012), in Arabidopsis seedlings under arsenic stress (Leterrier et al., 2012), and in Lotus japonicus roots and leaves exposed to water stress (Signorelli et al., 2013). However, there are different environmental conditions (hypoxia, UV radiation, ozone, etc.) where protein tyrosine nitration has not been studied yet.

The nitroproteome analysis under certain stress conditions has allowed the identification of the induced proteins. Thus, in Arabidopsis leaves, up to eight different proteins undergoing Tyr-nitration and mainly involved in photosynthesis were identified (Cecconi et al., 2009). After infection with an avirulent bacterial pathogen (Pseudomonas syringae pv. Tomato), a general rise in the expression of those nitrated proteins was observed. Besides, three new nitrated proteins were detected, although they could not be identified (Cecconi et al., 2009). High light conditions induced specific tyrosine nitration in the protein PSBA(D1) of PhotosystemII (PSII) which provoked a dissociation of the PSII dimers and PSII-LHCII supercomplexes and a possible subsequent degradation of damaged protein subunits (Galetskiy et al., 2011). The exposure of sunflower seedlings to HT caused both oxidative and nitrosative stress, and nitroproteome analysis showed an increase in 12 tyrosine-nitrated proteins compared to control plants, plus the detection of a newly nitrated protein, a carbonic anhydrase (CA) (Chaki et al., 2011). Among the tyrosine-nitrated proteins under HT stress, two of them were investigated in more detail, ferredoxin-NADP reductase (FNR) and CA, since both enzymes are involved in photosynthetic 
Table 1 | Examples of proteins identified in higher plants which are targets of tyrosine nitration, and the effect of this PTM on their function.

\begin{tabular}{|c|c|c|c|c|c|}
\hline Protein & Plant species & $\begin{array}{l}\text { Subcellular } \\
\text { localization }\end{array}$ & Effects & $\begin{array}{l}\text { Identified } \\
\text { nitrated Tyr }\end{array}$ & References \\
\hline S-adenosyl homocysteine hydrolase (SAHH) & Sunflower & Nucleus & Decreased activity & Tyr-448 & Chaki et al., 2009a \\
\hline Ferredoxin-NADP reductase & Sunflower & Chloroplast & Decreased activity & ND & Chaki et al., 2011 \\
\hline Carbonic anhydrase ( $\beta$-CA) & Sunflower & Chloroplast & Decreased activity & Tyr-205a & Chaki et al., 2013 \\
\hline PSBA(D1) of Photosystem II complex & Arabidopsis & Chloroplast & $\begin{array}{l}\text { Disassembly of } \\
\text { PSIl dimers }\end{array}$ & Tyr-262 ${ }^{b}$ & Galetskiy et al., 2011 \\
\hline Methionine synthase & Arabidopsis & Cytosol & Decreased activity & Tyr-287b & Lozano-Juste et al., 2011 \\
\hline Glutamine synthetase & $\begin{array}{l}\text { Medicago } \\
\text { truncatula }\end{array}$ & $\begin{array}{l}\text { Cytosol } \\
\text { Chloroplast }\end{array}$ & Decreased activity & ND & Melo et al., 2011 \\
\hline O-acetylserine(thiol) lyase A1 & Arabidopsis & Cytosol & Decreased activity & Tyr-302b & Álvarez et al., 2011 \\
\hline Glyceraldehyde-3-phosphate dehydrogenase & $\begin{array}{l}\text { Arabidopsis } \\
\text { thaliana }\end{array}$ & $\begin{array}{l}\text { Cytosol } \\
\text { Chloroplast }\end{array}$ & Decreased activity & ND & Lozano-Juste et al., 2011 \\
\hline NADP-isocitrate dehydrogenase & Pea & Cytosol & Decreased activity & Tyr-392 ${ }^{b}$ & Begara-Morales et al., 2013 \\
\hline$\alpha$-Tubulin & $\begin{array}{l}\text { Rice and tobacco } \\
\text { cell cultures }\end{array}$ & Microtubules & Mitosis inhibition & ND & Jovanović et al., 2010 \\
\hline
\end{tabular}

a In silico identification.

${ }^{b}$ Mass spectrometric techniques (LC-MS/MS).

ND: Not determined.

carbon assimilation, a process very sensitive to HT. Under HT stress the activities of FNR and CA were inhibited by $31 \%$ and $43 \%$, respectively. This inhibition was corroborated under in vitro conditions, where their respective activities were determined in the presence of peroxynitrite as nitrating agent (Chaki et al., 2011, 2013).

Nitration can also provoke a loss of function as observed for different plant enzyme activities analyzed in vitro including ascorbate peroxidase and catalase (Clark et al., 2000), $S$-adenosyl homocysteine hydrolase (Chaki et al., 2009b), and O-acetylserine(thiol)lyase Al activities (Álvarez et al., 2011).

\section{NITRATION AND PLANT DEVELOPMENT}

As indicated above, tyrosine nitration has been associated with situations of nitro-oxidative stress. However, some data illustrate the existence of a physiological protein nitration, which is not directly related to specific adverse conditions. Thus, in sunflower seedlings grown under optimal conditions, nitroproteome analysis of hypocotyl samples allowed the identification of 21 nitrotyrosine-immunopositive proteins involved in photosynthesis, and antioxidative, ATP, carbohydrate, and nitrogen metabolisms (Chaki et al., 2009b). More recently, nitroproteome analysis of Citrus roots revealed 26 potential candidate proteins to nitration (Tanou et al., 2012). Moreover, comparison of the nitroproteomes from green and red mature pepper (Capsicum annuum L.) fruits allowed identifying, by 2D gel and immunoblot, the profile of nitrated proteins which changed from 21 immunoreactive spots to 31 during fruit ripening. This could mean that protein tyrosine nitration could be used as an indicator of the ripening process in fruits. In rice seedlings and in tobacco BY-2 suspension cells grown under normal conditions, tyrosine nitration of $\alpha$-tubulin may inhibit cell division and consequently cell growth as mitosis is inhibited (Jovanović et al., 2010).

Recently, nitration analysis during development and senescence of different organs from 8, 12, 14, and 16-day-old (young), and 71-day-old (senescent) pea plants has shown that each organ has its own protein nitration pattern (Figure 1B). In the case of roots, it was observed that the intensity of nitrated proteins increased with root age. Roots of senescent pea plants contained 16 nitrotyrosine-immunoreactive proteins. Among the identified proteins, cytosolic NADP-isocitrate dehydrogenase, an enzyme involved in carbon and nitrogen metabolism, redox regulation, and response to oxidative stress, was studied to determine the effect of nitration during root senescence, a developmental stage which produced a significant decrease of its activity (BegaraMorales et al., 2013).

\section{CONCLUSIONS}

In higher plants, there is a growing interest in the analysis of protein tyrosine nitration as well as the identification of in vivo nitrated proteins. These studies are difficult to accomplish since tyrosine nitration is a low-abundance PTM. For example, in animal organisms under inflammatory conditions the estimated frequency of tyrosine nitration is 1 out of 10,000 tyrosines (Radi, 2004). The available data in higher plants are generally based on 2D gel electrophoresis and immunoblotting, what have provided some specific nitroproteomes including 21 proteins in sunflower cotyledons (Chaki et al., 2009a), 16 proteins in pea roots (BegaraMorales et al., 2013), and 127 proteins in Arabidopsis whole seedlings (Lozano-Juste et al., 2011). The identification of specific nitroproteomes from different plant organs under natural and stress conditions will be an exciting challenge for incoming research. Additionally, the study of the nitroproteome at subcellular level can provide fundamental data on cell proteomics of plants under different conditions.

\section{ACKNOWLEDGMENTS}

Work in our laboratories has been supported by ERDFcofinanced grants from the Ministry of Science and Innovation (BIO2009-12003-C02-01 and BIO2009-12003-C02-02, AGL2011-26044, and ACI2009-0860) and Junta de Andalucía (project AGR-6374, groups BIO192 and BIO286), Spain. 


\section{REFERENCES}

Abello, N., Kerstjens, H. A., Postma, D. S., and Bischoff, R. (2009). Protein tyrosine nitration: selectivity, physicochemical and biological consequences, denitration, and proteomics methods for the identification of tyrosine-nitrated proteins. J. Proteome Res. 8, 3222-3238.

Airaki, M., Leterrier, M., Mateos, R. M., Valderrama, R., Chaki, M., Barroso, J. B., et al. (2012). Metabolism of reactive oxygen species and reactive nitrogen species in pepper (Capsicum annuum L.) plants under low temperature stress. Plant Cell Environ. 35, 281-295.

Álvarez, C., Lozano-Juste, J., Romero, L. C., García, I., Gotor, C., and León, J. (2011). Inhibition of Arabidopsis Oacetylserine(thiol)lyase Al by tyrosine nitration. J. Biol. Chem. 86, 578-586.

Arasimowicz-Jelonek, M., and Floryszak-Wieczorek, J. (2011). Understanding the fate of peroxynitrite in plant cells-from physiology to pathophysiology. Phytochemistry 72, 681-688.

Begara-Morales, J. C., Chaki, M., Sánchez-Calvo, B., Mata-Pérez, C., Leterrier, M., Valderrama, R., et al. (2013). Protein tyrosine nitration in pea roots during development and senescence. J. Exp. Bot. 64, doi: 10.1093/jxb/ert006. [Epub ahead of print].

Cecconi, D., Orzetti, S., Vandelle, E., Rinalducci, S., Zolla, L., and Delledonne, M. (2009). Protein nitration during defense response in Arabidopsis thaliana. Electrophoresis 30, 2460-2468.

Cellini, A., Corpas, F. J., Barroso, J. B., and Masia, A. (2011). Nitric oxide content is associated with tolerance to bicarbonate-induced chlorosis in micropropagated Prunus explants. J. Plant Physiol. 168, 1543-1549.

Chaki, M., Carreras, A., LópezJaramillo, J., Begara-Morales, J. C., Sánchez-Calvo, B., Valderrama, R., et al. (2013). Tyrosine nitration provokes inhibition of carbonic anhydrase $(\beta-\mathrm{CA})$ activity under high temperature stress. Nitric Oxide 29C, 30-33.

Chaki, M., Valderrama, R., FernándezOcaña, A. M., Carreras, A., Gómez-Rodríguez, M. V., LópezJaramillo, J., et al. (2011). High temperature triggers the metabolism of $S$-nitrosothiols in sunflower mediating a process of nitrosative stress which provokes the inhibition of ferredoxin-NADP reductase by tyrosine nitration. Plant Cell Environ. 34, 1803-1818.

Chaki, M., Valderrama, R., FernándezOcaña, A. M., Carreras, A., López-Jaramillo, J., Luque, F., et al. (2009a). Protein targets of tyrosine nitration in sunflower (Helianthus annuus L.) hypocotyls. J. Exp. Bot. 60, 4221-4234.

Chaki, M., Fernández-Ocaña, A. M., Valderrama, R., Carreras, A., Esteban, F. J., Luque, F., et al. (2009b). Involvement of reactive nitrogen and oxygen species (RNS and ROS) in sunflower-mildew interaction. Plant Cell Physiol. 50, 265-279.

Clark, D., Durner, J., Navarre, D. A., and Klessig, D. F. (2000). Nitric oxide inhibition of tobacco catalase and ascorbate peroxidase. Mol. Plant Microbe Interact. 13, 1380-1384.

Corpas, F. J., Chaki, M., FernándezOcaña, A., Valderrama, R., Palma, J. M., Begara-Morales, J. C., et al. (2008). Metabolism of reactive nitrogen species in pea plants under abiotic stress conditions. Plant Cell Physiol. 49, 1711-1722.

Corpas, F. J., Chaki, M., Leterrier, M., and Barroso, J. B. (2009). Protein tyrosine nitration: a new challenge in plants. Plant Signal. Behav. 4, 1-4.

Corpas, F. J., del Río, L. A., and Barroso, J. B. (2007). Need of biomarkers of nitrosative stress in plants. Trends Plant Sci. 12, 436-438.

Dekker, F., Abello, N., Wisastra, R., and Bischoff, R. (2012). Enrichment and detection of tyrosine-nitrated proteins. Curr. Protoc. Protein Sci. 69, 14.13.1-14.13.19.

Galetskiy, D., Lohscheider, J. N., Kononikhin, A. S., Popov, I. A., Nikolaev, E. N., and Adamska, I. (2011). Phosphorylation and nitration levels of photosynthetic proteins are conversely regulated by light stress. Plant Mol. Biol. 77, 461-473.

Gow, A. J., Farkouh, C. R., Munson, D. A., Posencheg, M. A., and Ischiropoulos, H. (2004). Biological significance of nitric oxidemediated protein modifications. Am. J. Physiol. Lung Cell Mol. Physiol. 287, L262-L268.

Greenacre, S. A., and Ischiropoulos, H. (2001). Tyrosine nitration: localisation, quantification, consequences for protein function and signal transduction. Free Radic. Res. 34, 541-581.

Ischiropoulos, H. (2003). Biological selectivity and functional aspects of protein tyrosine nitration. Biochem. Biophys. Res. Commun. 305, 776-783.

Jovanović, A. M., Durst, S., and Nick, P. (2010). Plant cell division is specifically affected by nitrotyrosine. J. Exp. Bot. 61, 901-909.

Leterrier, M., Airaki, M., Palma, J. M., Chaki, M., Barroso, J. B., and Corpas, F. J. (2012). Arsenic triggers the nitric oxide (NO) and $S$-nitrosoglutathione (GSNO) metabolism in Arabidopsis. Environ. Pollut. 166, 136-143.

Lozano-Juste, J., Colom-Moreno, R. and León, J. (2011). In vivo protein tyrosine nitration in Arabidopsis thaliana. J. Exp. Bot. 62, 3501-3517.

Melo, P. M., Silva, L. S., Ribeiro, I., Seabra, A. R., and Carvalho, H. G. (2011). Glutamine synthetase is a molecular target of nitric oxide in root nodules of Medicago truncatula and is regulated by tyrosine nitration. Plant Physiol. 157, 1505-1517.

Morot-Gaudry-Talarmain, Y., Rockel, P., Moureaux, T., Quilleré, I., Leydecker, M. T., Kaiser, W. M. et al. (2002). Nitrite accumulation and nitric oxide emission in relation to cellular signaling in nitrite reductase antisense tobacco. Planta 215, 708-715.

Radi, R. (2004). Nitric oxide, oxidants, and protein tyrosine nitration. Proc. Natl. Acad. Sci. U.S.A. 101, 4003-4008.

Saito, S., Yamamoto-Katou, A. Yoshioka, H., Doke, N., and Kawakita, K. (2006). Peroxynitrite generation and tyrosine nitration in defense responses in tobacco BY-2 cells. Plant Cell Physiol. 47, 689-697.

Signorelli, S., Corpas, F. J., Omar Borsani, O., Barroso, J. B., and Monza, J. (2013). Water stress induces a differential and spatially distributed nitro-oxidative stress response in roots and leaves of Lotus japonicus. Plant Sci. 201-202, 137-146.

Sokolovsky, M., Riordan, J. F., and Vallee, B. L. (1967). Conversion of 3-nitrotyrosine to 3-aminotyrosine in peptides and proteins. Biochem. Biophys. Res. Commun. 27, 20-25.
Souza, J. M., Peluffo, G., and Radi, R. (2008). Protein tyrosine nitration -functional alteration or just a biomarker? Free Radic. Biol. Med. 45, 357-366.

Tanou, G., Filippou, P., Belghazi, M., Job, D., Diamantidis, G. Fotopoulos, V., et al. (2012). Oxidative and nitrosative-based signaling and associated posttranslational modifications orchestrate the acclimation of citrus plants to salinity stress. Plant J. 72, 585-599.

Valderrama, R., Corpas, F. J., Carreras, A., Fernández-Ocaña, A., Chaki, M., Luque, F., et al. (2007). Nitrosative stress in plants. FEBS Lett. 581, 453-461.

van der Vliet, A., Eiserich, J. P., Shigenaga, M. K., and Cross, C. E. (1999). Reactive nitrogen species and tyrosine nitration in the respiratory tract: epiphenomena or a pathobiologic mechanism of disease? Am. J. Respir. Crit. Care Med. $160,1-9$.

Ytterberg, A. J., and Jensen, O. N. (2010). Modification-specific proteomics in plant biology. J. Proteomics 73, 2249-2266.

Conflict of Interest Statement: The authors declare that the research was conducted in the absence of any commercial or financial relationships that could be construed as a potential conflict of interest.

Received: 03 December 2012; accepted: 06 February 2013; published online: 25 February 2013

Citation: Corpas FJ, Palma JM, del Río LA and Barroso JB (2013) Protein tyrosine nitration in higher plants grown under natural and stress conditions. Front. Plant Sci. 4:29. doi: 10.3389/fpls. 2013.00029

This article was submitted to Frontiers in Plant Proteomics, a specialty of Frontiers in Plant Science.

Copyright (C) 2013 Corpas, Palma, del Rio and Barroso. This is an openaccess article distributed under the terms of the Creative Commons Attribution License, which permits use, distribution and reproduction in other forums, provided the original authors and source are credited and subject to any copyright notices concerning any third-party graphics etc. 